\title{
Training in the Morris Water Maze Occludes the Synergism Between ACPD and Arachidonic Acid on Glutamate Release in Synaptosomes Prepared from Rat Hippocampus
}

\author{
Bernadette McGahon, ${ }^{1}$ Christian Holscher, ${ }^{2}$ Liam McGlinchey, ${ }^{2}$ \\ Michael J. Rowan, ${ }^{2}$ and Marina A. Lynch ${ }^{1,3}$ \\ ${ }^{1}$ Department of Physiology and \\ ${ }^{2}$ Department of Pharmacology and Therapeutics \\ Trinity College \\ Dublin 2, Ireland
}

\begin{abstract}
We report here that release of glutamate, inositol phospholipid metabolism, and protein kinase C (PKC) activity are increased in synaptosomes prepared from hippocampi of rats that had been trained in a spatial learning task. In hippocampi obtained from animals that were untrained, activation of the metabotropic glutamate receptor by the specific agonist trans-1-amino-cyclopentyl-1,3-dicarboxylate (ACPD) increased release of glutamate but only in the presence of a low concentration of arachidonic acid. A similar interaction between arachidonic acid and ACPD was observed on inositol phospholipid turnover and on PKC activity. However, the synergistic effect of arachidonic acid and ACPD on glutamate release was occluded in hippocampal synaptosomes prepared from trained rats. Occlusion of the effect on inositol phospholipid turnover and PKC activation was also observed. These data suggest that the molecular changes that underlie spatial learning may include activation of metabotropic glutamate receptors in the presence of arachidonic acid and that the interaction between arachidonic acid and ACPD triggers the presynaptic changes that accompany learning.
\end{abstract}

\footnotetext{
${ }^{3}$ Corresponding author.
}

\section{Introduction}

It is a widely held view that memory formation is dependent on changes in synaptic efficacy that allows strengthening (or weakening) of associations between neurons. The hippocampus has been identified as a brain area that plays a significant role in memory processing (Squire 1992), particularly processing of spatial memory (e.g., McNaughton et al. 1986; O'Keefe 1991), and though it has been extensively studied, the mechanisms that underlie acquisition and recall are not known. Certain cellular changes have been associated with learning; many of these have been identified as a result of comparison between young animals, which perform well in learning tasks, and aged animals, which often exhibit learning impairments (Barnes 1979), and in studies designed to investigate similarities and/or differences between learning and long-term potentiation (LTP). The hypothesis that LTP in the hippocampus is a biological correlate of learning and/or memory is actively challenged, but there is a good deal of indirect evidence lending support to this idea. Thus, it has been reported that AP5 blocks induction of LTP (see Bliss and Collingridge 1993) and also the ability of rats to perform in a spatial learning task (Morris et al. 1986), that both LTP and learning are associated with increased release of glutamate in dentate gyrus (Richter-Levin et al. 1994), and that protein kinase C (PKC) activity is increased following induction of LTP (Akers et al. 1986; Angenstein et al. 1994) and in a learning paradigm (Fordyce et al. 1994).

It has been reported recently that when acti-

LEARNING \& MEMORY 3:296-304 (c) 1996 by Cold Spring Harbor Laboratory Press ISSN1072-0502/96 $\$ 5.00$

$$
\begin{array}{llllllllllllllll}
\hline & E & A & R & N & I & N & G & \underset{296}{\mathbf{Q}} & M & E & M & O & R & Y
\end{array}
$$


vation of metabotropic glutamate receptors is blocked, learning in a spatial task is impaired (Richter-Levin et al. 1994), and this observation, as well as the finding that learning was accompanied by increased glutamate release in dentate gyrus, brings into the context of learning and recall the reports that trans-1-amino-cyclopentyl-1, 3-dicarboxylate (ACPD) and arachidonic acid (AA) act synergistically to increase release of glutamate in cortex (Herrero et al. 1992) and hippocampus (McGahon and Lynch 1994). AA has not yet been shown to play a role in spatial learning, but it has been implicated in learning in the chick (Hölscher and Rose 1994), and rat (Hölscher et al. 1995) and in maintenance of LTP in the dentate gyrus of the rat (Williams et al. 1989; Clements et al. 1991; Lynch and Voss 1994).

In designing these experiments, we considered that changes at the level of the synapse, resulting in "strengthening" of these synapses, probably accompany spatial learning and that presynaptic modifications are likely to contribute to these changes. In this study we have examined the effect of spatial learning on three parameters in hippocampal synaptosomes: glutamate release, inositol phospholipid metabolism, and PKC activation. In addition we have compared the effect of $\mathrm{AA}$ and $\mathrm{ACPD}$, alone and in combination, on these three parameters in synaptosomes prepared from hippocampus obtained from untrained rats and hippocampus obtained from rats that had been trained to locate a hidden platform in the Morris water maze. The data presented indicate that spatial learning increases glutamate release, inositol phospholipid metabolism, and PKC activation. Moreover, although AA and ACPD interact to further increase all three measures in synaptosomes prepared from untrained tissue, this effect is occluded in hippocampus obtained from trained rats.

\section{Materials and Methods}

\section{ANIMALS}

Male Wistar rats (250-300 grams) were used in these experiments. Animals were housed in groups of four to six under a 12-hr light schedule. The temperature was controlled between $22^{\circ} \mathrm{C}$ and $23^{\circ} \mathrm{C}$.

\section{TRAINING SCHEDULE}

A white fiberglass circular pool (diam., 120 $\mathrm{cm}$; height, $48 \mathrm{~cm}$; depth of water, $34 \mathrm{~cm}$ ) was used in these experiments. The platform (diam., $10 \mathrm{~cm}$ ) was $4 \mathrm{~cm}$ below the water surface during training. The water was kept at $23 \pm 2^{\circ} \mathrm{C}$ and made opaque with titanium dioxide. The pool was situated in a room with visual cues (e.g., door, window, curtain, etc.). All animals were marked with a black water-resistant marker to allow monitoring. The animals' movements were recorded with a video camera attached to the ceiling, and data was analyzed using a tracking program written by James Mahon (Trinity College, Dublin). During task aquisition, the program measured latency of animals to reach the platform and the distance covered. The pool was divided into four arbitrary quadrants for transfer test analysis. The quadrant in which the platform had been located (SE) was designated the target quadrant. During the transfer test, the percentage of the distance covered was assessed for each of the four quadrants.

Animals were placed in the water at one of four starting positions that alternated in a clockwise manner. Six trials were performed per day, and the intertrial interval was $\sim 5 \mathrm{~min}$. The cut-off time for a trial, if the animals failed to locate the platform, was $120 \mathrm{sec}$; in this case the animals were manually placed on the platform for $10 \mathrm{sec}$. On day 4, the platform was removed and the animals were given a 60 -sec duration transfer test in the pool. The group that did not learn the task were given six swimming sessions in the pool each day without a platform. The duration of the session was the same as that of the group of animals that learned the task.

Animals were sacrificed by cervical dislocation 10-15 min after completion of the behavioral test. The hippocampus was dissected free; the time taken for this dissection was $\sim 1 \mathrm{~min}$. Slices ( 350 $\mu \mathrm{m}$ ) were prepared using a Mcllwain tissue chopper, suspended in Krebs solution, thoroughly mixed, and divided into three aliquots for later assessment of glutamate release, inositol phospholipid metabolism, and PKC activity. Slices were frozen in Krebs solution containing 10\% DMSO (Haan and Bowen 1981) and stored in three separate aliquots in liquid $\mathrm{N}_{2}$ until required for analysis.

\section{TISSUE PREPARATION}

Slices were thawed rapidly (1.5-2 $\mathrm{min})$ by agitation at $37^{\circ} \mathrm{C}$ and rinsed four times in excess fresh oxygenated Krebs solution. Tissue was homogenized in $0.32 \mathrm{M}$ ice-cold sucrose and centri-

$$
\text { ….... 圈" }
$$


fuged at $5000 \mathrm{rpm}$ for $5 \mathrm{~min}$. The crude synaptosomal pellet, $\mathrm{P}_{2}$, was prepared by centrifuging the resulting supernatant at $15,000 \mathrm{rpm}$ for $15 \mathrm{~min} . \mathrm{P}_{2}$ was used for analysis of glutamate release, inositol phospholipid metabolism, and PKC activity. All biochemical analysis was completed on all samples that were tested in the behavioral paradigm.

\section{ASSESSMENT OF GLUTAMATE RELEASE}

Synaptosomes were resuspended in ice-cold Krebs solution (composition in mM: $\mathrm{NaCl}, 136$; $\mathrm{KCl}, 2.54 ; \mathrm{KH}_{2} \mathrm{PO}_{4}, 1.18 ; \mathrm{MgSO}_{4} \cdot 7 \mathrm{H}_{2} \mathrm{O}, 1.18$; $\mathrm{NaHCO}_{3}, 16$; glucose, 10) containing $2 \mathrm{mM} \mathrm{CaCl}_{2}$ and incubated for $15 \mathrm{~min}$ at $37^{\circ} \mathrm{C}$ in the presence of $\left[{ }^{3} \mathrm{H}\right]$ glutamate (Amersham, UK; specific activity, 20-40 Ci/mmole; final concentration, $5 \times 10^{-7}$ $\mathrm{mm})$. Tissue was aliquoted onto Millipore filters $(0.45 \mu \mathrm{m})$ and rinsed under vacuum at least 20 times by addition of $250 \mu \mathrm{l}$ of ice-cold, oxygenated, fresh Krebs solution to the filter papers. Tissue was then incubated for $5 \mathrm{~min}$ at $37^{\circ} \mathrm{C}$ in $250 \mu \mathrm{l}$ oxygenated Krebs solution with no added calcium or with Krebs solution containing $2 \mathrm{~mm} \mathrm{CaCl}_{2}$. The filtrate was discarded. This step was repeated, but incubation continued for $10 \mathrm{sec}$. [In earlier experiments, we investigated release at different incubation times $(10,20$, and $60 \mathrm{sec}$ and $5 \mathrm{~min})$. Small time-related differences in the proportions of calcium-independent and calcium-dependent release were observed and because a greater proportion of calcium-dependent release was observed in the shorter time period, the 10 -sec incubation period was chosen. This finding is consistent with the literature, which indicates that calcium-dependent release is initially very rapid, whereas calcium-independent release increases linearly with time (e.g., Nicholls 1989).] Filtrate was collected for scintillation counting. The incubation step was repeated, but in this case $40 \mathrm{~mm} \mathrm{KCl}$ was added to depolarize the synaptosomes. In some cases AA (final concentration, $1 \mu \mathrm{M}$ ), ACPD (50 $\mu \mathrm{M})$, or both were added during the incubation period to examine the effects of these agents on unstimulated and $\mathrm{KCl}$-stimulated release. Results from previous experiments indicated that higher concentrations of AA increase release of glutamate in the absence as well as in the presence of calcium and also interfere with glutamate uptake (Lynch and Voss 1990); a final concentration of $1 \mu \mathrm{M} \mathrm{AA}$ was chosen in these experiments to avoid these con- founding effects. In preliminary experiments, release of $\left[{ }^{3} \mathrm{H}\right]$ glutamate was compared in synaptosomes prepared in sucrose alone and in sucrose to which bovine serum albumin (BSA) was added to remove polyunsaturated fatty acid that may have been released during preparation. No difference between the two groups was observed, and, so, the experiments described here were performed on slices that were prepared in the absence of BSA.

\section{ANALYSIS OF INOSITOL PHOSPHOLIPID TURNOVER}

To examine $\left[{ }^{3} \mathrm{H}\right]$ inositol labeling of phosphoinositides and inositol phosphates, synaptosomes were resuspended in oxygenated ice-cold Krebs buffer (composition in mM: $\mathrm{NaCl}, 136 ; \mathrm{KCl}, 2.54$; $\mathrm{KH}_{2} \mathrm{PO}_{4}, 1.18 ; \mathrm{MgSO}_{4} \cdot 7 \mathrm{H}_{2} \mathrm{O}, 1.18 ; \mathrm{NaHCO}_{3}, 16 ;$ $\mathrm{CaCl}_{2}, 1.3$; glucose, 10; cytidine, $\left.1 ; \mathrm{LiCl}, 5\right)$ and aliquots $(50 \mu \mathrm{l})$ were incubated at $37^{\circ} \mathrm{C}$ for 35 min in a shaking water bath in $120 \mu$ Krebs buffer containing $\left[{ }^{3} \mathrm{H}\right]$ myoinositol (final concentration, $0.3 \mu \mathrm{M}$; specific activity, $110 \mathrm{mCi} / \mathrm{mg}$; Amersham, UK). AA ( $10 \mu \mathrm{l}$; final concentration, $1 \mu \mathrm{M})$ or ACPD ( $10 \mu \mathrm{l}$; final concentration, $50 \mu \mathrm{M})$ or an equivalent volume of control vehicle was added to the synaptosomal suspension at that point, and incubation continued for a further $35 \mathrm{~min}$. In some experiments, both ACPD (final concentration, 50 $\mu \mathrm{M}$ ) and AA (final concentration, $1 \mu \mathrm{M}$ ) were present in the incubation medium. The final assay volume was $250 \mu \mathrm{l}$ in all experiments. The reaction was terminated by addition of ice-cold trichloroacetic acid ( $18 \mu \mathrm{l}$; final concentration, $5 \%$ ), $940 \mu \mathrm{l}$ of chloroform/methanol 2:3 (vol/ vol), $310 \mu \mathrm{l}$ of chloroform, and $310 \mu \mathrm{l}$ of water. Organic and aqueous layers were vortex mixed and separated by centrifugation. To assess $\left[{ }^{3} \mathrm{H}\right]$ inositol labeling of inositol phosphates, aliquots ( 400 $\mu \mathrm{l}$ ) of the aqueous phase were added to $1 \mathrm{ml}$ of Dowex slurry (formate form, $\mathbf{5 0 \%}$ in water; Dowex-1, 8\% cross-linked, 200 mesh, Sigma) and washed four times with myoinositol ( $5 \mathrm{~mm}$ ). Inositol phosphates were eluted with $500 \mu \mathrm{l}$ of $0.1 \mathrm{M}$ $\mathrm{NH}_{4} \mathrm{OH}$ in $0.1 \mathrm{~m}$ formic acid. Aliquots $(400 \mu \mathrm{l})$ of the eluate were added to scintillation fluid for scintillation counting and calculation of total labeling of inositol phosphates by $\left[{ }^{3} \mathbf{H}\right]$ inositol. To assess labeling of phosphoinositides by $\left[{ }^{3} \mathrm{H}\right]$ inositol, aliquots $(320 \mu \mathrm{l})$ of the lower organic phase were evaporated overnight, scintillant was added, and samples counted for radioactivity. The protein

$$
\text { ….... }
$$


concentration was estimated by the method of Bradford (1976), and all values were expresed as $\mathrm{cpm} / \mu \mathrm{g}$ protein.

\section{ANALYSIS OF PKC}

PKC activity was examined using an enzyme assay system (Amersham, UK) that assessed transfer of the radiolabeled phosphate group from adenosine-5-triphosphate ( $\left.\left[{ }^{32} \mathrm{P}\right] \mathrm{ATP}\right)$ to histone, a peptide specific for $\mathrm{PKC}$. $\mathrm{P}_{2}$ was prepared and lysed by incubating at $4^{\circ} \mathrm{C}$ for $10 \mathrm{~min}$ in lysis buffer [composition: $5 \mathrm{~mm}$ Tris- $\mathrm{HCl}$ at $\mathrm{pH} 7.5$, containing 5 mм EDTA, 10 mм EGTA, 0.3\% (wt/vol) $\beta$-mercaptoethanol, $10 \mathrm{~mm}$ benzamidine, and $50 \mu \mathrm{l} / \mathrm{ml}$ of phenylmethylsulphonyl fluoride]. The membrane fraction was pelleted and resuspended in assay buffer [composition: $50 \mathrm{~mm}$ Tris- $\mathrm{HCl}$ at $\mathrm{pH}$ 7.5, containing $5 \mathrm{~mm}$ EDTA, $10 \mathrm{~mm}$ EGTA, 0.3\% (wt/vol) $\beta$-mercaptoethanol, $10 \mathrm{~mm}$ benzamidine and $50 \mu \mathrm{l} / \mathrm{ml}$ of phenylmethylsulphonyl fluoride]. The reaction was started by addition of $\left[{ }^{32} \mathrm{P}\right] \mathrm{ATP}$ to the synaptosomal suspension, which was then incubated at $25^{\circ} \mathrm{C}$ for $15 \mathrm{~min}$. In some experiments, the effect of AA (final concentration, $1 \mu \mathrm{M}$ ), ACPD ( $50 \mu \mathrm{M}$ ), or both was assessed; in this case the compounds were added prior to the $15-\mathrm{min}$ incubation period. The final assay volume was 75 $\mu l$. Phosphorylated peptide was separated by applying the reaction mixture to binding paper and washing with $5 \%$ (vol/vol) acetic acid. Binding papers were added to scintillant and ${ }^{32} \mathrm{P}$ counted. Results were expressed as picomoles phosphate transferred per minute.

\section{STATISTICAL ANALYSIS}

A one-way analysis of variance was performed to determine whether there were significant differences between conditions. When this analysis indicated significance (at the 0.05 level), post hoc Student's Newmann Keuls test analysis was used to determine which conditions were significantly different from each other. In some cases the Student's $t$-test for independent means was used to establish statistical significance.

\section{MATERIALS}

ACPD was obtained from Tocris (UK); AA and other standard chemicals were obtained from
Sigma (UK). All radiochemicals and the PKC assay kit were obtained from Amersham (UK).

\section{Results}

\section{TRAINING}

The animals that were trained in the water maze task learned the task in the acquisition trials. The period of time required to locate the platform was reduced from $102 \mathrm{sec}$ in trial 1 to $8 \mathrm{sec}$ in trial 18 (Fig. 1). In the transfer task, untrained control animals, which swam in the pool during the acquisition phase without a platform, did not show a preference for any quadrant (ANOVA over all quadrants, $F(3,20)=2.4, P>0.05 ; n=6)$. In contrast, animals that were trained, spent a greater proportion of time in the SE quadrant (the target quadrant) than in any of the other quadrants (ANOVA over all quadrants, $F(3,20)=21$, $P<0.001 ; n=6)$. A two-tailed unpaired $t$-test showed a significant difference in the distance swum in the SE quadrant by the trained group compared with the untrained control group ( $t=3.09$ with 10 degrees of freedom; $P<0.02$ ). Within the trained group, there was a significant difference in the distance swum in the target quadrant (SE) compared with the distance swum in the opposite quadrant (NW quadrant; $t=7.1$ with 10 degrees of freedom; $P<0.001 ; n=6$ ).
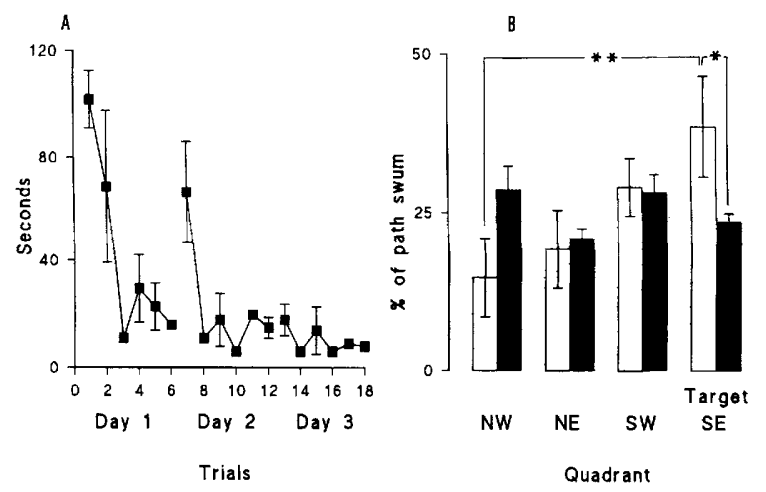

Figure 1: (A) Time required to locate a hidden platform in a water maze. The period of time required to locate the platform was reduced from $102 \mathrm{sec}$ in the first trial to $8 \mathrm{sec}$ in the eighteenth trial. (B) Percentage of path swum by rats in a transfer task without a platform. Trained rats swam a greater distance in the target (SE) quadrant compared with the opposite (NW) quadrant $(P<0.001)$. Trained rats also swam a significantly greater distance in the target quadrant than untrained rats $(P<0.02)$.

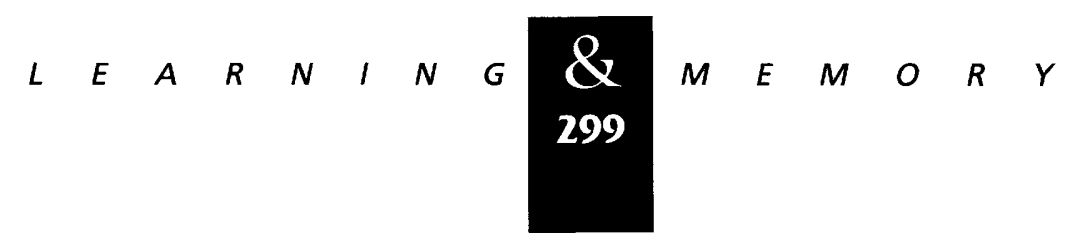




\section{EFFECTS OF AA AND ACPD ON GLUTAMATE RELEASE}

Mean accumulation of $\left[{ }^{3} \mathrm{H}\right]$ glutamate was similar in tissue prepared from rats that were untrained and those that were trained in the Morris water maze $(12,285 \pm 983$ vs. $12,854 \pm 1794$, respectively). Mean unstimulated release was also similar in synaptosomes prepared from trained and untrained rats $(0.096 \% \pm 0.008$ and $0.11 \% \pm 0.007$, respectively). Addition of $40 \mathrm{~mm} \mathrm{KCl}$ to the incubating medium significantly increased glutamate release in the absence of calcium, but a further significant increase was observed in the presence of calcium (data not shown). Figure 2A shows that $\mathrm{KCl}$-stimulated glutamate release (i.e., release in the presence of $40 \mathrm{~mm} \mathrm{KCl}$ minus unstimulated release) in the presence of calcium was significantly greater in hippocampal synaptosomes prepared from trained rats compared with untrained rats $(P<0.05$; Student's $t$-test for independent means). Neither AA (1 $\mu \mathrm{M})$ nor ACPD (50 $\mu \mathrm{M})$ alone had any significant effect on release in hippocampal synaptosomes prepared from untrained rats ("control synaptosomes"), but AA and ACPD together induced a significant increase in release $(P<0.001$; ANOVA $)$. As in the case of control synaptosomes, neither AA nor ACPD alone had any significant effect on release of glutamate in synaptosomes prepared from tissue obtained from trained rats. However, in contrast to the effect in control synaptosomes, there was no evidence of the synergism between AA and ACPD on release in synaptosomes prepared from hippocampus obtained from trained rats (Fig. 2A).

\section{EFFECT OF AA AND ACPD ON INOSITOL PHOSPHOLIPID METABOLISM}

Labeling of total inositol phospholipids with $\left[{ }^{3} \mathrm{H}\right]$ inositol was used as an index of inositol phospholipid turnover. $\left[{ }^{3} \mathrm{H}\right]$ inositol labeling of phosphoinositides was similar in synaptosomes prepared from trained and untrained rats, and no significant effect of AA, ACPD, or both together was observed (data not shown). Figure $2 \mathrm{~B}$ shows that inositol phospholipid turnover was significantly increased in synaptosomes prepared from hippocampus of trained rats compared with untrained rats $(P<0.05$; Student's $t$-test for independent means). In control synaptosomes, both AA ( $1 \mu \mathrm{M})$ and ACPD ( $50 \mu \mathrm{M})$ significantly increased inositol phospholipid turnover $(P<0.05$ in each case; ANOVA); the increase was significantly greater in the presence of both AA and ACPD $(P<0.01$ compared with control; $P<0.05$ compared with AA alone or ACPD alone; ANOVA). In synaptosomes prepared from tissue obtained from trained rats, neither AA nor ACPD alone nor both agents together had any significant effect on inositol phospholipid metabolism (Fig. 2B).

\section{EFFECT OF AA AND ACPD ON PKC ACTIVITY}

Figure $2 \mathrm{C}$ demonstrates that activity of PKC was significantly enhanced in synaptosomes prepared from tissue obtained from trained rats compared with control $(P<0.001$; Student's $t$-test for independent means). AA ( $1 \mu \mathrm{M})$ and ACPD ( 50 $\mu \mathrm{M})$ alone significantly enhanced PKC activity in "control" tissue $(P<0.05$ in each case) but when both AA and ACPD were included in the incubation medium, a further increase was observed $(P<0.001$ compared with control; $P<0.05$ compared with AA alone or ACPD alone; ANOVA). In contrast to the observations in control synaptosomes, neither AA nor ACPD had any significant effect on PKC activity in synaptosomes prepared from hippocampus of trained rats. Moreover, the interaction between AA and ACPD on PKC activity, which was clearly evident in control tissue, was absent in these synaptosomes (Fig. 2C).

\section{Discussion}

The hypothesis that memory formation requires modification at the level of the synapse is central to the growing number of investigations designed to identify the mechanisms underlying learning and/or memory. In the present experiments we examined one specific form of learning, that is, training in the Morris water maze, and investigated the possibility that this leads to changes in the presynaptic terminal in hippocampus thereby contributing to an alteration in synaptic strength. The results show enhanced release of glutamate, inositol phospholipid metabolism, and PKC activity in synaptosomes prepared from animals that had undergone training in a spatial learning task. We also report that the synergism between $\mathrm{AA}$ and ACPD on these three measures, which we observe in hippocampi obtained from

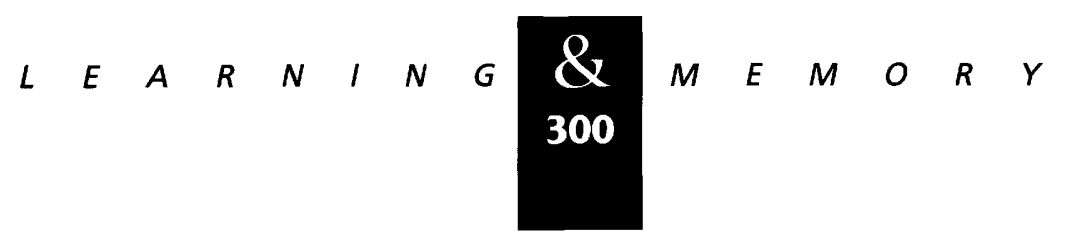



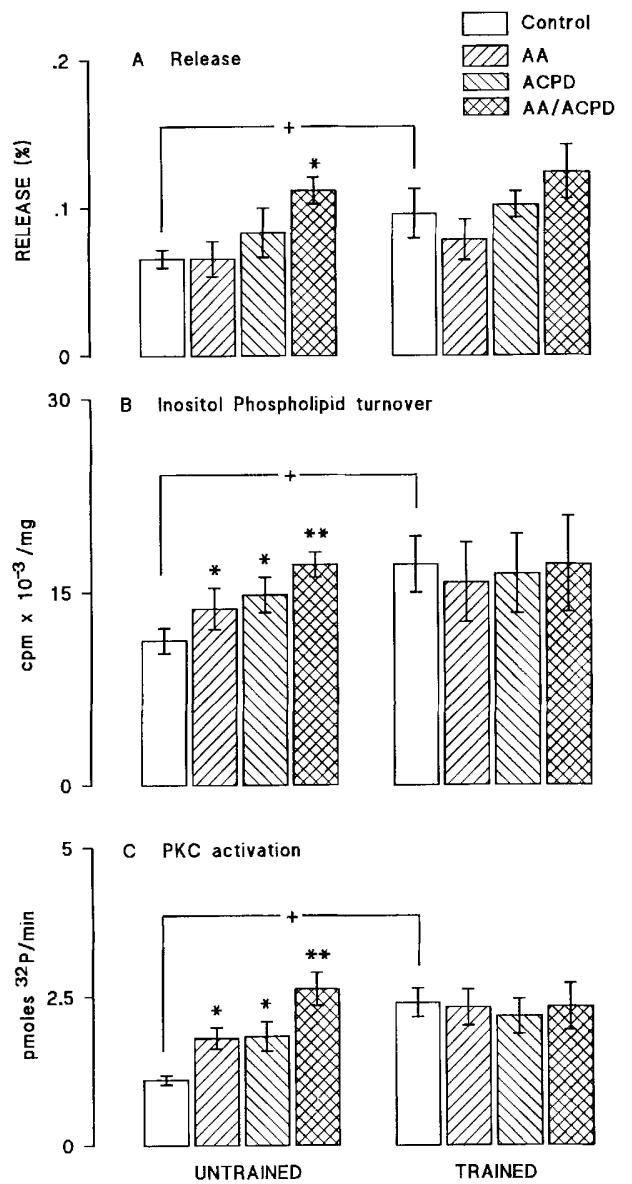

Figure 2: (A) Potassium stimulated calcium-dependent release of $\left[{ }^{3} \mathrm{H}\right.$ lglutamate in synaptosomes prepared from hippocampus obtained from trained and untrained rats: effect of ACPD and AA. AA and ACPD, in combination (but neither alone), significantly increased $\mathrm{KCl}$-stimulated glutamate release ( $P<0.001$; one-way ANOVA). Release was significantly increased in synaptosomes prepared from hippocampus obtained from trained rats, compared with untrained $(+P<0.05$; Student's $t$-test for independent means). No effect of AA or ACPD, alone or in combination, affected release hippocampal synaptosomes prepared from trained animals. Results were calculated by subtracting basal release from $\mathrm{KCl}$-stimulated release, and individual values were used to calculate the mean \pm S.E.M. for six observations. Release is expressed as a percentage of the radiolabel present at the start of the incubation period. (B) Inositol phospholipid metabolism in synaptosomes prepared from hippocampus obtained from trained and untrained rats: effect of ACPD and AA. AA $(1 \mu \mathrm{M})$ and ACPD $(50 \mu \mathrm{M})$ significantly increased inositol phospholipid metabolism in hippocampal synaptosomes prepared from untrained rats (control synaptosomes; ${ }^{*} P<0.01$; ANOVA); in combination, AA and ACPD increased inositol phospholipid metabolism to a greater extent $\left({ }^{* *} P<0.001\right.$ compared with control; $P<0.05$ compared with either AA or ACPD alone). Inositol phospholipid metabolism was significantly increased in hippocampal synaptosomes prepared from trained rats, compared with control $(+P<0.05$; Student's $t$-test for independent means), but neither AA nor ACPD nor both agents had any effect in synaptosomes prepared from trained rats. Values are means ( \pm S.E.M.) of six observations and are expressed as cpm $\left(\times 10^{-3}\right)$ / mg protein. (C) PKC activity in synaptosomes prepared from trained and untrained rats: effect of ACPD and AA. AA (1 $\mu \mathrm{M})$ and ACPD $(50 \mu \mathrm{M})$ significantly increased PKC activity in hippocampal synaptosomes prepared from untrained rats $\left({ }^{*} P<0.05\right.$; ANOVA); in combination, AA and ACPD increased PKC activity to a greater extent ( ${ }^{* *} P<0.001$ compared with control; $P<0.05$ compared with either AA or ACPD alone). PKC activity was significantly increased in hippocampal synaptosomes pre-

pared from trained rats, compared with untrained rats $(+P<0.05$; Student's $t$-test for independent means); but no effect of $\mathrm{AA}, \mathrm{ACPD}$, or both agents together was observed in hippocampal synaptosomes prepared from trained rats. Values are means ( \pm S.E.M.) of six observations and are expressed as picomoles phosphate incorporated $/ \mathrm{min}$.

untrained rats, was occluded in hippocampi obtained from trained rats.

The present data indicate that a low concentration of AA did not affect glutamate release, supporting earlier reports (Herrero et al. 1992; McGahon and Lynch 1994) and contrasting with the inhibitory effect of higher concentrations (Lynch and Voss 1990). The finding that ACPD had no effect on release indicates that it is unlikely to activate a presynaptic glutamate receptor that functions as an autoreceptor, although such a receptor has been observed in neonates (Baskys 1992). Although no effect of either AA or ACPD alone was observed, these agents acted synergistically to increase glutamate release in synaptosomes prepared from hippocampi of untrained animals, supporting earlier observations in the cortex (Herrero et al. 1992), whole hippocampus
(McGahon and Lynch 1994), and dentate gyrus (McGahon and Lynch 1996). This effect was absent in hippocampal synaptosomes prepared from trained rats. This observation suggests that training occluded this effect, although it must be considered that other factors, for example, stress, may have contributed to the changes. Because ACPD is a nonspecific activator of mGluRs, it is not possible to speculate on the receptor subtype activated in these experiments. However, because previous evidence suggests that coupling to cAMP is unlikely (McGahon and Lynch 1994) and because PLC activation is stimulated by ACPD, it might be speculated that mGluR1 or mGluR5 may play a role (Pin and Duvoisin 1995).

The increase in release of glutamate described here supports the recent observation of RichterLevin et al. (1995) who reported that training in a

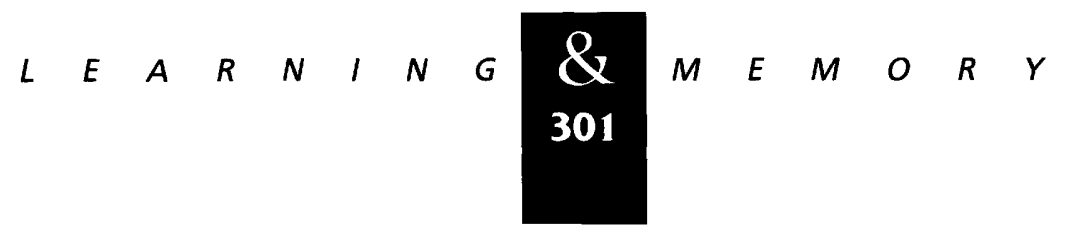


spatial learning task was associated with increased glutamate release in dentate gyrus. In the present study, tissue was prepared $15 \mathrm{~min}$ after the trans. fer test, whereas in the study of Richter-Levin, tissue was prepared $4 \mathrm{hr}$ after testing, and, therefore, it is possible that recall contributes to a greater extent to the changes described in the present study. It is of interest that classical conditioning has also been associated with increased glutamate release in dentate gyrus (Laroche et al. 1987). The fact that increased glutamate release is a feature of both learning and maintenance of LTP (Lynch et al. 1989; Canevari et al. 1994) supports the idea that LTP may be a biological substrate for learning and memory. Further support of this nature is presented here, because we have found that the synergism between AA and ACPD on glutamate release in dentate gyrus was occluded by prior induction of LTP in this area (McGahon and Lynch 1996).

In an effort to establish the mechanisms underlying the AA/ACPD-induced increase in glutamate release, we examined the effect of these agents on inositol phospholipid metabolism, an increase that leads to formation of inositol trisphosphate $\left(\mathrm{IP}_{3}\right)$ and diacylglycerol. Both second messengers have the ability to increase transmitter release, by increasing intracellular calcium concentration and PKC activity, respectively. The data presented indicate that training in the Morris water maze led to an increase in inositol phospholipid metabolism in whole hippocampus. Changes in inositol phospholipid metabolism in behavioral paradigms have been reported previously; associative learning is accompanied by an increase in basal inositol phospholipid metabolism in the three subfields of the hippocampus (Laroche et al. 1990), while training in an eight-arm radial maze is accompanied by an increase in ibotenate-induced, but not basal, inositol phospholipid metabolism (Nicoletti et al. 1986). We report here that both AA and ACPD increased inositol phospholipid metabolism, as described previously in the case of AA (Lynch et al. 1988; Lynch and Voss 1990) and as described in other brain areas in the case of ACPD (Schoepp et al. 1990; Pin and Duvoisin 1995). In addition to these responses, we found that $\mathrm{AA}$ and ACPD interacted to further increase inositol phospholipid metabolism, confirming our previous observation (McGahon and Lynch 1994). In parallel with our release data, we found that the stimulatory effects of AA and ACPD, alone and in combination, were occluded in synaptosomes prepared from trained animals. These parallel effects suggest that the increase in glutamate release may derive from increased inositol phospholipid metabolism.

It is well established that $\mathrm{IP}_{3}$ increases intracellular calcium concentration in several systems, including in synaptosomes prepared from dentate gyrus (Lynch and Voss 1991), and this may contribute to release; activation of PKC also stimulates transmitter release (Parfitt and Madison 1993; Terrian et al. 1993). One interpretation of these results is that the increase in glutamate release observed here is a consequence of increased inositol phospholipid metabolism. The occlusion of the effects of AA and ACPD on inositol phospholipid metabolism by training in the water maze is similar to the occlusion observed following induction of LTP (McGahon and Lynch 1996), lending indirect support to the idea that the mechanisms underlying spatial learning resemble those underlying maintenance of LTP.

Both AA and ACPD alone significantly enhanced PKC activity in synaptosomes prepared from hippocampus obtained from untrained rats, and the combination of the two agents induced a further increase in whole hippocampus as described previoulsy (McGahon and Lynch 1994). In parallel with the occlusion of the AA/ACPD synergism on release and inositol phospholipid metabolism by training, the data indicate that the interaction between AA and ACPD on PKC is also occluded. Training also occluded the separate actions of AA and ACPD on PKC. The close coupling in reponses of phospholipase $\mathrm{C}$ and $\mathrm{PKC}$ to $\mathrm{AA}$ and ACPD, both alone and in combination, suggests that PKC activation may be secondary to phospholipase $\mathrm{C}$ activation. AA has been shown to activate PKC (Murakami and Routtenberg 1985), but the present results suggest that this may be secondary to an effect on inositol phospholipid metabolism.

There is a good deal of evidence suggesting that activation of PKC plays a role in spatial learning. Thus, physical activity that increases performance in a spatial learning task also increases PKC activity (Fordyce et al. 1994). In addition, PKC activity in hippocampus of aged mice (C57) with learning impairments was found to be reduced compared with aged mice $\left(F_{1}\right)$ in which no agerelated learning impairment was observed (Fordyce and Wehner 1993). It has also been shown that performance in the Morris water maze was correlated positively with PKC substrate phosphorylation (Wong et al. 1989). It is of interest

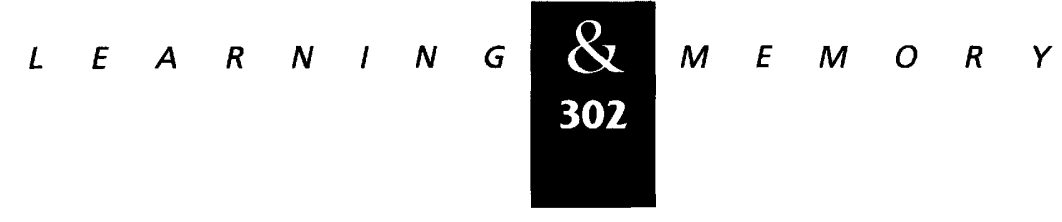


that increased activation of PKC following induction of LTP has been reported (Akers et al. 1986; Angenstein et al. 1994; Pasinelli et al. 1995), as well as an increase in presynaptic PKC activity in area CA1 (Leahy et al. 1993). Although indirect, the parallel responses in PKC activity following a learning paradigm and induction of LTP, provide further support for the notion that LTP is a biolog. ical substrate for learning and/or memory.

One interpretation of the data presented here is that spatial learning induces changes in inositol phospholipid metabolism leading to PKC activation, and that these changes, in turn, lead to an increase in glutamate release. The inference is that this sequence of events will occur as a consequence of $\mathrm{mGluR}$ activation in the presence of $\mathrm{AA}$. However, it is possible that training modifies release of other transmitters and that these may impact on glutamate release.

Our proposal is that learning induces changes presynaptically that lead to increased glutamate release and therefore a strengthening of certain synapses. Our data suggest that the increase in release may derive from increased inositol phospholipid metabolism and thence increased $\mathrm{PKC}$ activation. Because the effects of AA and ACPD, alone and together, are occluded in synaptosomes prepared from trained animals, it is tempting to conclude that an interaction between these compounds lies at the heart of the changes induced by training and therefore plays a pivotal role in the process of synaptic strengthening.

\section{Acknowledgments}

We wish to acknowledge the generous financial support of The Health Research, Ireland, and The Sandoz Foundation for Gerontological Research.

\section{References}

Akers, R.F., D.M. Lovinger, P.A. Colley, D.J. Linden, and A. Routtenberg. 1986. Translocation of protein kinase $C$ may mediate hippocampal long-term potentiation. Science 231: $587-589$.

Angenstein, F., G. Riedel, K. Reymann, and S. Staak. 1994. Hippocampal long-term potentiation in vivo induces translocation of protein kinase C. NeuroReport 5: 381-384.

Barnes, C.A. 1979. Memory deficits associated with senescence: A neurophysiological and behavioural study in the rat. I. Comp. Physiol. Psychol. 93: 74-104.
Baskys, A. 1992. Metabolic glutamate receptors and slow excitatory actions of glutamate agonists in the hippocampus. Trends Neurosci. 15: 92-96.

Bliss, T.V.P. and G.L. Collingridge. 1993. A synaptic model of memory: Long-term potentiation in the hippocampus. Nature 361: 31-39.

Bradford, M.M. 1976. A rapid and sensitive method for the quantitation of microgram quantities of proteins utilizing the principle of protein dye binding. Anal. Biochem. 72: 248-254.

Canevari, L., G. Richter-Levin, and T.V.P. Bliss. 1994. LTP in the dentate gyrus is associated with a persistent NMDA receptor-dependent enhancement of synaptosomal glutamate release. Brain Res. 667: 115-117.

Clements, M.P., T.V.P. Bliss, and M.A. Lynch. 1991. Increase in arachidonic acid in a postsynaptic membrane fraction following the induction of long-term potentiation in the dentate gyrus. Neuroscience 45: 379-389.

Fordyce, D.E. and J.M. Wehner. 1993. Effects of aging on spatial learning and hippocampal protein kinase $C$ in mice. Neurobiol. Aging 14: 309-317.

Fordyce, D.E., R.V. Bhat, J.M. Baraban, and J.M. Wehner. 1994. Genetics and activity-dependent regulation of Zif268 expression: Association with spatial learning. Hippocampus 4: $559-568$.

Haan, E.A. and D.M. Bowen. 1981. Protection of neocortical prisms from freeze-thaw injury by dimethylsulphhoxide. I. Neurochem. 37: 243-246.

Herrero, I., M.T. Miras-Portugal, and J. Sanchez-Prieto. 1992. Positive feedback of glutamate exocytosis by metabotropic presynaptic receptor stimulation. Nature 360: $163-166$.

Hölscher, C. and S.P.R. Rose. 1994. Inhibitors of phospholipase $A_{2}$ produce amnesia for a passive avoidance task in the chick. Behav. Neural Biol. 61: 225-232.

Hölscher, C., L. Canevari, and G. Richter-Levin. 1995. Inhibitors of $\mathrm{PLA}_{2}$ and $\mathrm{NO}$ synthase cooperate in producing amnesia of a spatial task. NeuroReport 6: 730-732.

Laroche, S., M.L. Errington, M.A. Lynch, and T.V.P. Bliss. 1987. Increase in $\left[{ }^{3} \mathrm{H}\right]$-glutamate release from slices of dentate gyrus and hippocampus following classical conditioning in the rat. Behav. Biochem. Res. 25: 23-29.

Laroche, S., C. Redini Del Negro, M.P. Clements, and M.A. Lynch. 1990. Long-term activation of phosphoinositide turnover associated with increased release in amino acids in the dentate gyrus and hippocampus following classical conditioning in the rat. Eur. J. Neurosci. 2: 534-543.

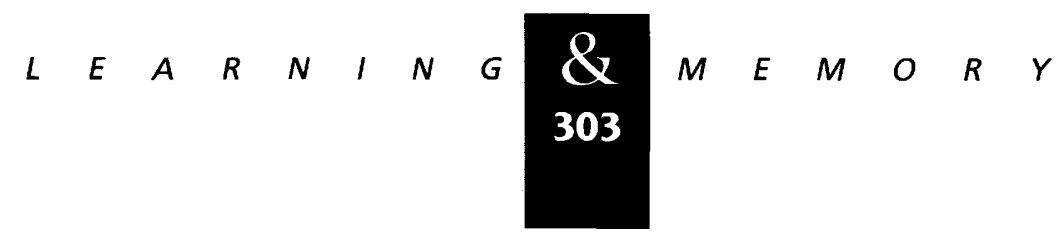


Leahy, J.C., Y. Luo, C.S. Kent, K.F. Meiri, and M.L. Vallano. 1993. Demonstration of presynaptic protein kinase $C$ activation following long-term potentiation in rat hippocampal slices. Neuroscience 52: 563-574.

Lynch, M.A. and K.L. Voss. 1990. Arachidonic acid increases inositol phospholipid metabolism and glutamate release in synaptosomes prepared from hippocampal tissue. ). Neurochem. 55: 215-221.

1991. Presynaptic changes in long-term potentiation: Elevated synaptosomal calcium concentration and basal phosphoinositide turnover in dentate gyrus. J. Neurochem. 56: $113-118$.

1994. Membrane arachidonic acid concentration correlates with age and induction of long-term potentiation in the dentate gyrus of the rat. Eur. J. Neurosci. 6: 1008-1014.

Lynch, M.A., M.P. Clements, M.L. Errington, and T.V.P. Bliss. 1988. Increased hydrolysis of phosphatidylinositol-4,5-bisphosphate in long-term potentiation. Neurosci. Lett. 84: 291-296.

Lynch, M.A., M.L. Errington, and T.V.P. Bliss. 1989. The increase in $\left[{ }^{3} \mathrm{H}\right]$-glutamate release associated with long-term potentiation in the dentate gyrus is blocked by commissural stimulation. Neurosci. Lett. 103: 191-196.

McGahon, B. and M.A. Lynch. 1994. A study of the synergism between metabotropic glutamate receptor activation and arachidonic acid in the rat hippocampus. NeuroReport 5: 2353-2357.

1996. The synergism between metabotropic glutamate receptor activation and arachidonic acid on glutamate release is occluded by induction of long-term poteniation in dentate gyrus. Neuroscience 72: 847-855.

McNaughton, B.L., C.A. Barnes, G. Rao, J. Baldwin, and M. Rasmussen. 1986. Long-term enhancement of hippocampal synaptic transmission and the aquisition of spatial information. J. Neurosci. 6: 563-571.

Morris, R.G.M., E. Andersen, G. Lynch, and M. Baudry. 1986. Selective impairment of learning and blockade of long-term potentiation by an N-methyl-D-aspartate receptor antagonist, AP5. Nature 319: 774-776.

Murakami, K. and A. Routtenberg. 1985. Direct stimulation of purified protein kinase $C$ by unsaturated fatty acids (oleate, arachidonate) in the absence of phospholipids and calcium. FEBS Lett. 192: 189-193.

Nicoletti, F., C. Valerio, C. Pellegrino, F. Drago, U. Scapagnini, and P.L. Canonica. 1986. Spatial learning potentiates the stimulation of phosphoinositide hydrolysis by excitatory amino acids in rat hippocampus. J. Neurochem. 51: 725-729.

Nicholls, D.G. 1989. Release of glutamate, aspartate and aminobutyric acid from isolated nerve terminals. J. Neurochem. 52: 331-341.
O'Keefe, J. 1991. An allocentric spatial model for the hippocampal cognitive map. Hippocampus 1: 230-235.

Parfitt, K.D. and D.V. Madison. 1993. Phorbol esters enhance synaptic transmission by a presynaptic, calcium-dependent mechanism in rat hippocampus. I. Physiol. 471: 245-268.

Pasinelli, P., G.M.J. Ramakers, I.J.A. Urban, J.J.H. Hens, A.B. Oestreicher, P.N.E. deGrann, and W.H. Gispen. 1995. Long-term potentiation and synaptic protein phosphorylation. Behav. Brain Res. 66: 53-59.

Pin, J.-P. and R. Duvoisin. 1995. The metabotropic glutamate receptors: Structure and functions. Neuropharmacology 34: 1-26.

Richter-Levin, G., M.L. Errington, H. Maegawa, and T.V.P. Bliss. 1994. Activation of metabotropic glutamate receptors is necessary for long-term potentiation in the dentate gyrus and for spatial learning. Neuropharmacology 33: 853-857.

Richter-Levin, G., L. Canevari, and T.V.P. Bliss. 1995. Long-term potentiation and glutamate release in the dentate gyrus: Links to spatial learning. Behav. Brain Res. 66: 37-40.

Schoepp, D.D., J. Bockaert, and F. Sladeczek. 1990. Pharmacological and functional characteristics of metabotropic excitatory amino acid receptors. Trends Pharmacol. Sci. 11: 508-515.

Squire, L.R. 1992. Memory and the hippocampus: A synthesis from findings with rats, monkeys and humans. Psychol. Rev. 99: 195-231.

Terrian, D.M., D. Kirk-Ways, R.L. Gannon, and D.A. Zetts. 1993. Transduction of a protein kinase C-generated signal into the long-lasting facilitation of glutamate release. Hippocampus 3: 205-220.

Williams, J.H., M.L. Errington, M.A. Lynch, and T.V.P. Bliss. 1989. Arachidonic acid induces a long-term activity-dependent enhancement of synaptic transmission in the hippocampus. Nature 341: 739-742.

Wong, K.L., K. Murakami, and A. Routtenberg. 1989. Dietary cis-fatty acids that increase protein $F_{1}$ phosphorylation enhance spatial memory. Brain Res. 505: 302-305.

Received June 17, 1996; accepted in revised form August 22, 1996.

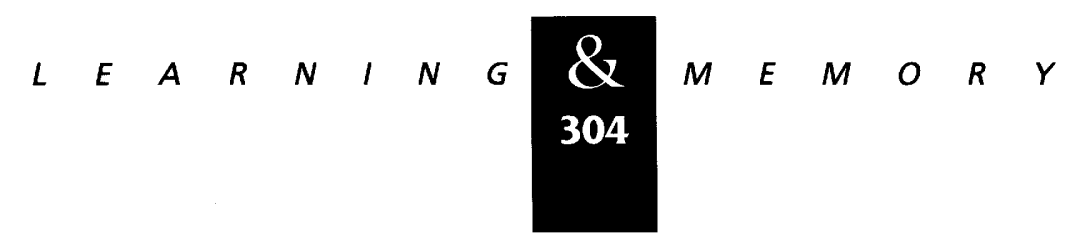




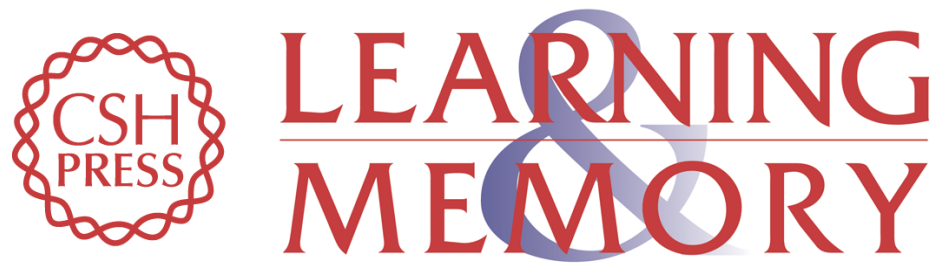

\section{Training in the Morris water maze occludes the synergism between ACPD and arachidonic acid on glutamate release in synaptosomes prepared from rat hippocampus.}

B McGahon, C Holscher, L McGlinchey, et al.

Learn. Mem. 1996, 3:

Access the most recent version at doi:10.1101//m.3.4.296

References This article cites 40 articles, 2 of which can be accessed free at: http://learnmem.cshlp.org/content/3/4/296.full.html\#ref-list-1

License

Email Alerting

Service

Receive free email alerts when new articles cite this article - sign up in the box at the top right corner of the article or click here. 